\title{
Persistent attenuation of brain oxidative stress through aging in perinatal maternal separated rat pups supplemented with choline and docosahexaenoic acid or Clitoria ternatea aqueous root extract
}

\author{
Prathibha Maria D Almeida ${ }^{1}$, Shobha Ullas Kamath ${ }^{2}$, Pooja R Shenoy ${ }^{2}$, Liegelin Kavitha Bernhardt ${ }^{1}$, Anoop Kishore ${ }^{3}$, \\ Kiranmai Sesappa Rai ${ }^{1}$ \\ ${ }^{1}$ Melaka Manipal Medical College, MAHE, Manipal, ${ }^{2}$ Kasturba Medical College, MAHE, Manipal, ${ }^{3}$ Manipal College of Pharmaceutical \\ Sciences, MAHE, Manipal, India
}

\begin{abstract}
Introduction: Perinatal maternal separation stress (PMSS) induces brain lipid peroxidation and reduction in endogenous antioxidants. The present study was designed to assess the brain oxidative stress (MDA) and protein thiol levels through various stages of aging in PMSS rat pups supplemented with choline with docosahexaenoic acid (DHA) or Clitoria ternatea (Linn) aqueous root extract (CTR).

Material and methods: Study groups, control, PMSS, PMSS + choline with DHA, PMSS + CTR ( $n=6 /$ group) were included in the study. Pups of PMSS groups were separated from their mothers for a period of $6 \mathrm{~h} /$ day for 30 days. PMSS + supplemented groups were treated as appropriate during the same period. Rats were sacrificed on day 30 , 60, 90, 210 and 360. Brains were processed for MDA and protein thiol levels.

Results: Brain MDA levels were significantly increased in PMSS rats at day 30, $60(p<0.001), 90(p<0.01)$ and attenuated in PMSS pups supplemented with choline with DHA and CTR at day 30, 60 ( $p<0.01), 90(p<0.01, p<0.05)$ and 360 ( $p<0.001)$ when compared to the same in age-matched controls and PMSS rats, respectively. Alternatively, brain protein thiol levels in PMSS rats were reduced in all age groups when compared to the same in age-matched controls. A significant increase in brain thiol levels was observed in supplemented groups at day $60(p<0.01)$ and $210(p<0.01, p<0.05)$ when compared to the same in age-matched PMSS rats.

Conclusions: PMSS causes enhanced brain lipid peroxidation (MDA levels) and reduces endogenous antioxidants. Supplementation of choline and DHA or CTR during PMSS in rats persistently attenuates brain oxidative stresS through aging.
\end{abstract}

Key words: choline, DHA, Clitoria ternatea, MDA, protein thiol. 


\section{Introduction}

Maternal employment persistently causes inadvertent separation of the mother from her child during working periods. Prolonged and continued separation stress can show long-lasting consequences for the development of the brain during brain growth spurt periods $[1,3,28]$. Chronic repeated perinatal maternal separation stress (PMSS) has proved to cause alteration in behaviour, neurochemical and structural modifications in the brain $[24,33,40]$. Maternal separation in humans during their childhood has caused a larger cortisol awakening response and flatten slopes in diurnal cortisol levels [27]. Studies show that PMSS induces oxidative stress and increases lipid peroxidation in various regions of the brain in adolescent male rats $[10,55]$ and also increases DNA breaks in the hippocampus [11].

Oxidative stress in the brain tissue is due to overproduction of reactive oxygen species (ROS) and free radicals, which overwhelms the endogenous antioxidant capacity of the brain $[14,36]$. Free radicals, such as $\mathrm{O}_{2}^{-}$(superoxide radical), $\mathrm{OH}$ (hydroxyl radical), and ROS (reactive oxygen species) such as $\mathrm{H}_{2} \mathrm{O}_{2}$ (hydrogen peroxide), NO (nitric oxide) cause damage to cell components including proteins, lipids with breaks in DNA and affect cellular signalling $[14,16]$.

The brain is more prone to oxidative damage than any other part of the body as it uses more oxygen, contains high fatty acids levels which are more susceptible to peroxidation, is rich in iron levels and excitatory amino acids and neurotransmitters, metabolism of which produces ROS [14]. ROS and free radicals affect glial cells and neurons leading to neural cell damage. Oxidative damage causes premature aging, atherosclerosis, neurodegenerative diseases [16]. Studies show that lipid peroxidation is increased in normal aging and associated with a decrease in endogenous antioxidant levels [18]. Malondialdehyde (MDA) is a product of lipid peroxidation and an indicator of oxidative stress [37].

Oxidative stress in turn causes protein oxidation and decreases endogenous antioxidant levels [5]. Protein thiols (-SH) make a maximum portion of total endogenous antioxidants in the body and play a major role in defence against ROS [36]. Studies show that brain protein thiol levels decrease in oxidative stress induced by chronic administration of aspartame. Protein thiol levels in the brain were also found to decrease in aged rats when compared to young rats. Additionally, aged male rat brains were found to have higher protein thiol levels than the same in females. A decrease in protein thiol levels and increase in lipid peroxidation in the old age is associated with a decline in memory [46].

Supplemental antioxidants along with endogenous antioxidants help decrease the effect of oxidative stress on cells by scavenging the ROS $[5,46]$. Intake of fruits and vegetables having high antioxidant levels is important in preventing oxidative stress and improves the antioxidant defence system of the body [41]. Choline is an essential brain nutrient that is present in several foods and is required for membrane structural integrity [61]. Administration of choline to women caused decrease in oxidative stress levels [47]. Dietary deficiency of choline increases lipid peroxidation in hepatocellular cells [48] and apoptosis in the foetal brain $[9,60]$. Similarly, docosahexaenoic acid (DHA) is another essential dietary nutrient. Studies show that DHA supplementation to male albino rats attenuates aluminium-mediated oxidative damage in the cerebellum by decreasing lipid peroxidation [7]. Studies also show that DHA-connecting phospholipid supplementation in diabetic mice is observed to decrease brain lipid peroxidation and increase $\alpha$-tocopherol levels [19]. Neuroprotectin D1 (NPD1) is a bioactive metabolic product of DHA, which protects the brain cell damage due to oxidative stress by up-regulating anti-apoptotic Bcl-2 proteins, decreasing pro-apoptotic Bax and Bad expression and inhibiting oxidative stress-induced caspase-3 activation [6]. Similarly, in Ayurvedic preparations, several herbs are used in Medhya rasayana (brain tonic) that are observed to contain antioxidants [56]. One such herb used in Medhya rasayana is Clitoria ternatea (Linn), whose aqueous root extract contains antioxidants and flavonoids [32,38] and its extracts are used in food products like 'Shankhapushpi' used as a memory enhancer. Earlier studies show that Clitoria ternatea aqueous root extract (CTR) increases acetylcholine levels in the rat hippocampus [43] and also increases dendritic arborization of CA3 pyramidal neurons in the rat hippocampus and improves the learning and memory in young adult rats $[23,42,44,45]$. It is also known to have anxiolytic, anti-stress, anticonvulsant, and antioxidant properties [22,35,53].

However, there are no studies showing the long-lasting persistent influence on the early life 
perinatal maternal separation stress and the influence of dietary supplementation containing exogenous antioxidants during the stress period in boosting the antioxidant levels in the aging brain. There are ethical limitations associated with conducting experiments in humans, so laboratory animal models were developed to experimentally investigate early environmental influence on behaviour and neurobiology [15]. We hypothesize that supplementation of either choline with DHA or CTR during the perinatal maternal separation stress period to rat pups will persistently boost the brain antioxidant system through aging.

The present study was designed to assess:

1. MDA and protein thiol (-SH) levels (brain oxidative stress) in perinatal maternal separation stressed (PMSS) rats through various stages of aging;

2. The long-term effects of choline with DHA or CTR supplements given to rat pups during the perinatal maternal stress period on MDA and protein thiol (-SH) levels through aging.

\section{Material and methods}

\section{Animals}

The study was conducted in accordance with CPCSEA guidelines and the guidelines laid down by the Institutional Animal Ethical Committee (IAEC/ KMC/99/2012). Inbred, pregnant female Wistar rats were procured from the central animal house. All the rats were housed in sanitized polypropylene cages containing sterile paddy husks as bedding. Animals were maintained under standard lab conditions of temperature $\left(23 \pm 2^{\circ} \mathrm{C}\right), 12$-h light-dark cycle in the Central Animal Research Facility and allowed to litter naturally. Rat pups aged post-natal day (PND) 2-30 were used for the study.

\section{Study design}

The study included five different groups of rat pups, i.e. group I, group II, group III, group IV and group $\mathrm{V}$, which were maintained till day 30, 60, 90, 210 and 360, respectively. Each group consisted of four subgroups $(n=6)$ as follows:

1. Normal control (NC),

2. Stressed (PMSS) + sterile water,

3. Stressed (PMSS) + choline + DHA,

4. Stressed (PMSS) + CTR.

Altogether 120 male rats were used for the whole study.

\section{Maternal separation stress procedure}

The date of litter birth of the rat pups were recorded as post-natal day 0 (PND 0) when they were procured. Pups from the normal control (NC) group were left undisturbed with their mothers, except during routine cage changes. Rat pups from the PMSS groups were separated from their mothers as per the procedure explained by George et al. [15]. These pups were separated from their mothers according to the following protocol, i.e. 4 hrs separation/day for pups aged PND 2-5, and 6 hrs separation/day for pups aged PND 6-21 as per standard guidelines. During the separation procedure, the pups from each of the PMSS groups were placed in a clean cage and housed in a separate room (room temperature maintained at $31-33^{\circ} \mathrm{C}$ to prevent hypothermia). This prevents mother-infant ultrasonic communication and also reach of odour of the mother since this may attenuate maternal separation effects on the pups. Handling was kept to a minimum at all times, to prevent buffering of the maternal separation effect. On PND 30, all pups were weaned and housed in groups of two or three pups/cage, to prevent isolation stress.

\section{Supplements and dosage}

Supplements were provided to appropriate PMSS rat pup groups only during the perinatal period till the day of weaning. Rat pups assigned to the PMSS groups received equal volume of sterile water from PND 2 to 21 and pups from PMSS + choline with DHA and PMSS + CTR groups were supplemented orally with choline and DHA or Clitoria ternatea aqueous root extract (CTR), respectively. The dosage was calculated according to the weight of the rat pups. Supplements were mixed with sterile water and administered orally with the help of a feeding tube.

Choline chloride: $42 \mathrm{mg} / \mathrm{kg}$ body weight (body wt.)/day (sigma) [43], DHA: $150 \mathrm{mg} / \mathrm{kg}$ body weight/day [sigma] [54], Clitoria ternatea aqueous root extract (CTR): $100 \mathrm{mg} / \mathrm{kg}$ b.w./day. Locally grown 2-3-year-old plants of Clitoria ternatea (white flowering variety) were identified and confirmed as Clitoria ternatea in the Department of Pharmacognosy, Manipal College of Pharmaceutical Sciences and by a botanist from the Mahatma Gandhi Memorial College (Government of India-aided college) where the voucher specimen of the plant was deposited in the college herbarium (MGM College Herbarium 
No. 9). Roots were collected for the preparation of the extract. Aqueous root extraction was done as per the method suggested by Rai et al. [43].

\section{Euthanization of rats at different stages of aging}

All the appropriate groups of rat pups (30-dayold rat pups, 60-day-old young adult rats, 90-day-old adult rats, 210-day-old middle-aged rats, 360-dayold aged rats) were subjected to PMSS and supplementation till postnatal day 30 and all the groups of rat pups were weaned on day 30 . They were subsequently maintained undisturbed in separate cages with four to five rats/cage. These rats were later sacrificed at different stages of aging as mentioned above i.e. on day $30,60,90,210$ and 360 by intraperitoneal administration of a high-dose Ketamine injection. Brains were removed and processed for the estimation of MDA and protein thiols.

\section{Preparation of brain tissue homogenate}

Brain tissue homogenates obtained from rats of different groups at different ages tested were processed in phosphate buffer saline $(\mathrm{pH} 7.4)$ using tissue homogenizer. Tissue homogenate was cold centrifuged at 10,000 rpm for 15 mins, and supernatant was separated and stored in $-20^{\circ} \mathrm{C}$ till further processing for estimation of MDA and thiol levels.

\section{Estimation of brain MDA levels}

Lipid peroxidation was measured in terms of the MDA: thiobarbituric acid (TBA) reaction. Briefly, the reaction mixture contained $0.1 \mathrm{ml}$ tissue homogenate, $0.2 \mathrm{ml}$ sodium dodecyl sulfate, $1.5 \mathrm{ml}$ acetic acid, and $1.5 \mathrm{ml}$ aqueous solution of TBA, heated at $95^{\circ} \mathrm{C}$ for $1 \mathrm{~h}$. The red pigment produced was extracted with n-butanol-pyridine mixture and estimated by the absorbance at $532 \mathrm{~nm}$ and the result was expressed in nanomoles/ml [53].

\section{Brain protein thiol assay}

Brain tissue thiol levels were estimated by the spectrophotometric method using dinitrobenzene (DTNB) - Ellman's method. DTNB reacted with -SH groups in proteins and reduced to stable intermediate compounds of mixed disulfide, protein s-s compound. The induced product of DTNB was 5-mer- capto-2 nitrobenzoate (MNB). The yellow colour developed was measured by the spectrophotometric method at the end of 5 minutes at $412 \mathrm{~nm}$. The absorbance was directly related to the amount of the thiol group present on proteins and the reading was compared with glutathione standard [12] and the result was expressed in $\mu$ moles/l.

\section{Statistical analysis}

Statistical analysis was done using statistical Graph Pad Software. Data obtained from the tests were expressed as mean \pm S.E.M. and analysed using one way ANOVA followed by Bonferroni's post hoc test with a significance level at $p<0.05$. Values of brain MDA levels were expressed in nanomoles per millilitre and for brain protein thiol levels in micromoles per litre.

\section{Results}

In the present study, brain MDA and protein thiol levels were estimated at different time points (ages) although interventions (PMS stress and supplementation provided to appropriate PMSS rat pup groups) were carried out only during the perinatal period till the day of weaning (30 days). In total, 24/120 animals were used in each age group (6 rats per group) to prepare brain tissue homogenate and used for the analysis of both MDA and protein thiol levels. Body weight of all the animals was measured regularly and it was observed that all the animals were of normal body weight and with normal health status. No death of animals was reported during the experimental period.

\section{Brain MDA levels}

Results of measured brain MDA levels were observed to be significantly increased in PMSS groups of rats at day $30(2.62 \pm 0.64)(p<0.001)$, $60(3.73 \pm 0.97)(p<0.001)$ and $90(1.67 \pm 0.83)$ $(p<0.01)$ when compared to the same in agematched normal control rats $(0.32 \pm 0.10),(0.45$ $\pm 0.30)$, (0.26 \pm 0.50$)$, respectively. Measured brain MDA levels were observed to be significantly attenuated in aging PMSS + choline with DHA as well as PMSS + CTR supplemented rats at day $30(1.01 \pm 0.26)$, (0.8 \pm 0.31$)(p<0.01), 60$ (0.81 \pm 0.30$),(0.68 \pm 0.28)$ ( $p<0.01), 90(0.25 \pm 0.01)(p<0.01),(0.48 \pm 0.06)$ $(p<0.05)$ and $360(0.098 \pm 0.01),(0.22 \pm 0.06)$ $(p<0.001)$ when compared to the same in age- 
matched PMSS rats $(0.50 \pm 0.04)$. But no significant difference in brain MDA levels was observed between PMSS + choline with DHA and PMSS + CTR supplemented rats at any of the age groups.

Interestingly, the measured brain MDA levels of the supplemented group of aging rats at day 360 days [PMSS + choline with DHA $(0.098 \pm 0.01)$ and PMSS + CTR $(0.22 \pm 0.06)]$ was observed to be persistently and significantly attenuated $(p<0.01)$ when compared to the measured brain MDA levels in agematched control rats $(0.41 \pm 0.05)$. No significant difference in brain MDA levels was observed between control $(0.41 \pm 0.05)$ rats and PMSS $(0.50 \pm 0.04)$ rats at day 360. At day 210, no significant difference in measured MDA levels was observed between any of the groups of rats [control $(0.38 \pm 0.03)$, PMSS $(0.45$ $\pm 0.13)$, PMSS + choline with DHA $(0.39 \pm 0.02)$, PMSS $+\operatorname{CTR}(0.38 \pm 0.03)]$ (Fig. 1).

\section{Brain protein thiol levels}

In the present study, at day 30, the measured brain protein thiol levels were observed to be significantly decreased $(p<0.001)$ in PMSS $(21.39$ $\pm 0.69)$, PMSS + choline with DHA $(29.88 \pm 6.42)$ and PMSS + CTR (31.66 \pm 2.50$)$ supplemented rat pups when compared to the same in age-matched controls (68.16 \pm 3.34 ). Alternately at day 60 and 210 , the measured brain protein thiol levels were significantly increased in PMSS + choline with DHA

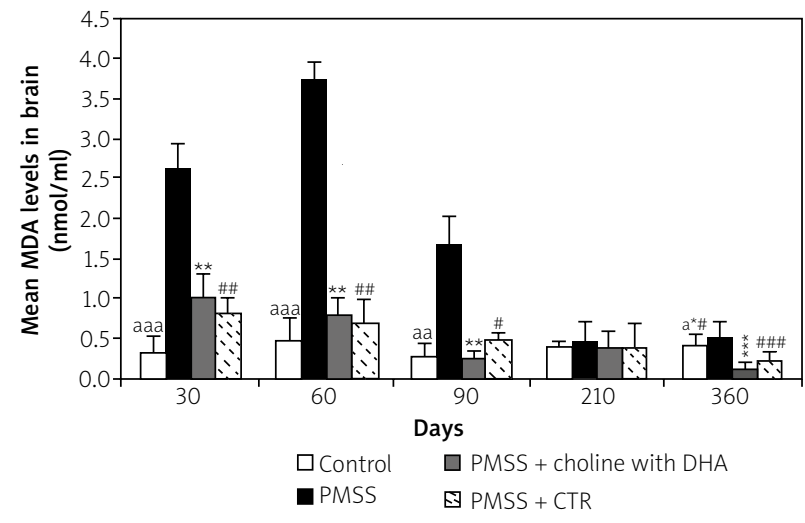

Fig. 1. MDA levels in brains of rats of experimental groups studied at different ages. Values are expressed as mean \pm SEM, significant levels tested by Bonferroni's post hoc test. $\# p<0.05,{ }^{\text {aa }}{ }^{* \star / \# \#} p<0.01,{ }^{\text {aaa } / * \star * / \# \# \# ~} p<0.001$ as compared to PMSS groups; ${ }^{{ }^{*} \# p}<0.001$ control vs. PMSS + choline with DHA and PMSS + CTR.
(151.33 \pm 13.39$),(334.62 \pm 23.59)(p<0.05 ; p<0.01)$ and PMSS + CTR supplemented rats $(145.8 \pm 11.30)$, (304.87 \pm 52$),(p<0.01)$, respectively, when compared to the same in age-matched PMSS rats ( 86.83 $\pm 17.76),(178.28 \pm 40.87)$. But at day 90 and 360 , the measured brain protein thiol levels in PMSS + choline with DHA (165.13 \pm 28.83$),(221.21 \pm 19.16)$ and PMSS + CTR (203.71 \pm 19.9$)(215.85 \pm 3.66)$ supplemented group although increased when compared to the same in age-matched PMSS rats (154.81 $\pm 11.21)(173.83 \pm 28.09)$, no statistical significance between the groups was observed (Fig. 2). No significant difference in brain thiol levels was observed between PMSS + choline with DHA and PMSS + CTR supplemented rats at any of the age groups.

\section{Discussion}

The purpose of this study was to elucidate the role of early life PMSS in rats and the possible long-lasting influence of the two supplements i.e. choline with DHA and Clitoria ternatea aqueous root extract (CTR), during the perinatal maternal separation stress period on brain lipid peroxidation levels and brain protein thiol levels at various time points during aging.

Increase in brain MDA (malondialdehyde) indicates excessive brain oxidative stress [41]. Results of the present study show that the brain MDA levels in the PMSS group of rats was consistently elevated at

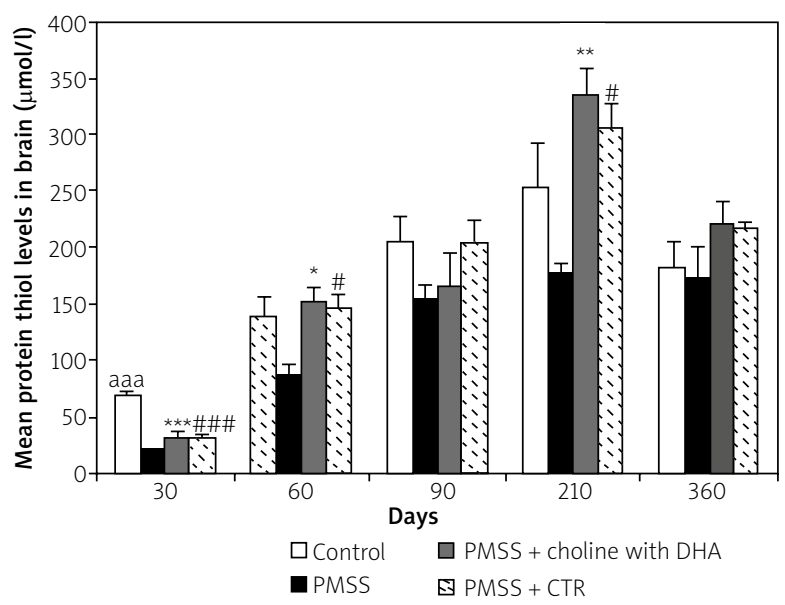

Fig. 2. Protein thiol levels in brains of rats of experimental groups studied at different ages. Values are expressed as mean \pm SEM, significant levels tested by Bonferroni's post hoc test. ${ }^{*} / \# p<0.05,{ }^{* *} p<0.01,{ }^{\text {aaa } / * * * / \# \# \#} p<0.001$ as compared to PMSS. 
different time points of aging tested. Increase in brain MDA levels in PMSS rats could be due to increased corticosterone levels induced by early life chronic stress similar to findings in earlier studies by Lehmann et al. [29]. Studies show that increase in glucocorticoids increases generation of reactive oxygen species (ROS) in the hippocampus and cortex [49]. Overproduction of ROS and free radicals overrides the endogenous antioxidant capacity of the brain and causes oxidative damage to the brain tissues and causes lipid peroxidation [4,31]. Moreover, studies show that lipid peroxidation increases with aging [2]. According to the 'free radical theory of aging', ROS and free radicals produced during aerobic respiration, damages cell components and connective tissues, causing cumulative damage over time, resulting in early changes of aging and death [17].

In the present study it was observed that supplementation of choline with DHA during PMSS caused persistent attenuation of brain MDA levels at different time points of aging. Dietary choline at different doses was previously observed to significantly decrease malondialdehyde, protein carbonyl contents in the spleen and kidney of juvenile Jian carp fishes [57]. Choline supplements were also observed to lower exercise-induced lipid peroxidation and increase serum Vitamin $A$ and $E$ levels in women [47]. In turn, studies show that dietary deficiency of choline increases hydrogen peroxide production in liver mitochondria by causing lipid peroxidation of hepatocytes [48]. DHA is another supplement used in this study whose high levels in brain tissue have been shown to decrease brain lipid peroxidation [59] and when supplemented as combined eicosapentaenoic acid-docosahexaenoic it decreases lipid peroxidation and increases antioxidant enzyme activity in brain of hypercholesterolemic rats [52]. Additionally other studies have observed that administration of the ethanolic extract of the whole Clitoria ternatea plant also reduces lipid peroxidation in acetaminophen-induced nephrotic damage [50]. Thus, the ability of supplements of choline and DHA or Clitoria ternatea aqueous root extract to lower lipid peroxidation is possibly due to their efficacy of modulating the brain tissue redox status in PMSS rats.

Alternatively, a decrease in the endogenous antioxidant status of the body may possibly enhance the susceptibility to deleterious effects of oxidative stress. Various stresses are known to cause protein oxidation that is marked by alterations in tissue protein thiol levels [36]. Protein thiols are the major endogenous antioxidant stores in the body that help reduce the activity of reactive oxygen species and minimize the redox status of the body [36]. In the present study it was observed that PMSS rats had decreased brain protein thiol levels that persisted through aging. Decreased thiol levels in PMSS rats could possibly be due to an increase in generation of ROS and free radicals that increasingly metabolize proteins and cause oxidation of thiol groups as observed in a study by Leichert et al. [30]. Alterations in protein thiols affect the cell function, cell signalling and apoptosis. Additionally, in aging there is a decrease in antioxidant levels and decrease in ROS scavenging activity $[18,51]$. Moreover, other studies also show that decrease in protein thiols is associated with increase in lipid peroxidation in parietal lobes of rats of the mimetic aging model $[25,55]$.

Many studies show that endogenous antioxidants help decrease the oxidative damage directly via reacting with free radicals or indirectly by inhibiting the activity or expression of free radical generating enzymes or enhancing the activity or expression of intracellular antioxidant enzymes [25,26]. Studies show that exogenous dietary supplements such as vitamin C, E, or herbs, which are rich in flavonoids and phenols, play a major role in improving the endogenous antioxidant pool in the body and thus decrease oxidative stress $[34,55,56]$. Results of the present study also show that supplementation of choline with DHA or CTR during PMSS in rat pups have a long-lasting influence on increasing thiol levels through aging. Choline supplementation to children with cystic fibrosis has shown to increase in SAM : SAH, methionine, and glutathione : GSSG levels in plasma [21]. Also Grass carp fishes fed with graded levels of dietary choline have shown to attenuate muscle oxidative damage, increase muscle antioxidant enzyme activity and up-regulation of NF-E2-related factor 2 transcripts (protein that regulates the expression of antioxidant proteins that protect against oxidative damage triggered by injury and inflammations) in their muscle tissue [57,62]. Studies show that intravenous and dietary supplemented DHA reduces protein oxidation [20]. Many in vitro studies have shown that dietary phenols and flavonoids derived from plants have antioxidant potentials $[8,32,56]$. CTR is a herbal supplement that contains phytochemicals such as amino acids, proteins, carbohydrates as well as alkaloids, saponins, flavonoids, coumarins, lignans, and 
phenols $[32,43]$. Studies show that the root of a white flowering variety of Clitoria ternatea has more antioxidant properties than the blue flowering variety [38]. In the present study, attenuating of the oxidative stress effect of CTR supplementation is possibly due to the presence of flavonoids, phenols and its antioxidant properties.

Limitations of the study: In this study, we had used male rat pups only. Therefore, we were not able to explore the effect of perinatal maternal separation stress in female rats through aging. This was due to feasibility issues. We plan to perform this experiment in the future as a continuation of the present study.

\section{Conclusions}

PMSS in rats causes an increase in brain oxidative stress by increasing lipid peroxidation (MDA levels) and reducing endogenous antioxidants (protein thiol levels) which are persistent through aging. Supplementation of choline with DHA or CTR during perinatal maternal separation stress in rat pups helps attenuate brain lipid peroxidation and enhance brain protein thiol levels persistently through aging. Further studies are needed to observe the influence of PMSS on changes in DNA methylation or histone acetylation and any such epigenetic alterations when supplemented with choline with DHA or CTR that attenuates PMSS-induced age-related changes on brain lipid peroxidation and endogenous antioxidant status.

\section{Acknowledgements}

Authors are thankful to MAHE for providing support and infrastructure to conduct this study.

\section{Disclosure}

The authors declare no conflict of interest.

\section{References}

1. Aisa B, Tordera R, Lasheras B, Rio DJ, Ramirez MJ. Effects of maternal separation on hypothalamic-pituitary-adrenal responses, cognition and vulnerability to stress in adult female rats. Neuroscienc 2008; 154: 1218-1226.

2. Akila VP, Harishchandra H, D'Souza V. Age related changes in lipid peroxidation and antioxidants in elderly people. Indian J Clin Biochem 2007; 22: 131-134.

3. Andersen SL, Teicher MH. Delayed effects of early stress on hippocampal development. Neuropsychopharmacology 2004; 29 1988-1993.
4. Baek BS, Kwon HJ, Lee KH, Yoo MA, Kim KW. Regional difference of ROS generation, lipid peroxidaton, and antioxidant enzyme activity in rat brain and their dietary modulation. Arch Pharm Res 1999; 22: 361-366.

5. Balu M, Sangeetha P, Murali G, Panneerselvam C. Age-related oxidative protein damages in central nervous system of rats: modulatory role of grape seed extract Int J Dev Neurosci 2005; 23: 501-507.

6. Bazan NG. Neuroprotectin D1 (NPD1): a DHA-derived mediator that protects brain and retina against cell injury-induced oxidative stress. Brain Pathol 2005; 15: 159-166.

7. Chaudhary M, Joshi DK, Tripathi S, Kulshrestha S, Mahdi AA. Docosahexaenoic acid ameliorates aluminum induced biochemical and morphological alteration in rat cerebellum. Ann Neurosci 2014; 21: 5-9.

8. Cittadini MC, Canalis AM, Albrecht C, Soria EA. Effects of oral phytoextract intake on phenolic concentration and redox homeostasis in murine encephalic regions. Nutr Neurosci 2015; 18: 316-322.

9. da Costa KA, Rai KS, Craciunescu CN, Parikh K, Mehedint MG, Sanders LM, McLean-Pottinger A, Zeisel SH. Dietary docosahexaenoic acid supplementation modulates hippocampal development in the Pemt-/- mouse. J Biol Chem 2010; 285: 1008-1015.

10. Daniels WM, Marais L, Stein DJ, Russell VA. Exercise normalizes altered expression proteins in the ventral hippocampus of rats subjected to maternal of separation. Exp Physiol 2012; 97 : 239-247.

11. Diehl LA, Alvares LO, Noschang C, Engelke D, Andreazza AC, Gonçalves CA, Quillfeldt JA, Dalmaz C. Long-lasting effects of maternal separation on an animal model of post-traumatic stress disorder: effects on memory and hippocampal oxidative stress. Neurochem Res 2012; 37: 700-707.

12. Ellman GL, Courtney KD, Andres V, Featherstone RM. A new and rapid colorimetric determination of acetylcholinesterase activity. Biochem Pharmacol 1961; 7: 88-95.

13. Evans CR, Miller N, Paganga G. Antioxidant properties of phenolic compounds. Trends Plant Sci 1997; 2: 152-159.

14. Floyd RA, Carney JM. Free radical damage to protein and DNA: mechanisms involved and relevant observations on brain undergoing oxidative stress. Ann Neurol 1992; 32 Suppl: S22-S27.

15. George ED, Bordner KA, Elwafi HM, Simen AA. Maternal separation with early weaning: a novel mouse model of early life neglect. BMC Neurosci 2010; 11: 123.

16. Gilgun-Sherki Y, Melamed E, Offen D. Oxidative stress induced-neurodegenerative diseases: the need for antioxidants that penetrate the blood brain barrier. Neuropharmacology 2001; 40: 959-975.

17. Harman D. Free radical theory of aging: an update. Ann N Y Acad Sci 2006; 1067: 10-21.

18. Hasan M, Tripathi S, Ali Mahdi A, Mitra K, Singh Negi MP. Lipofuscin, lipid peroxidation and antioxidant status in discrete regions of the aged rat brain. Proc Indian Natl Sci Acad 2009; 75: 173.

19. Hiratsuka S, Ishihara K, Kitagawa T, Wada S, Yokogoshi H. Effect of dietary docosahexaenoic acid connecting phospho- 
lipids on the lipid peroxidation of the brain in mice. J Nutr Sci Vitaminol (Tokyo) 2008; 54: 501-506.

20. Huang WL, King VR, Curran OE, Dyall SC, Ward RE, Lal N, Priestley JV, Michael-Titus AT. A combination of intravenous and dietary docosahexaenoic acid significantly improves outcome after spinal cord injury. Brain 2007; 130: 3004-3019.

21. Innis SM, Davidson AGF, Melynk S, James SJ. Choline-related supplements improve abnormal plasma methionine-homocysteine metabolites and glutathione status in children with cystic fibrosis. Am J Clin Nutr 2007; 85: 702-708.

22. Jain N, Ohal CC, Shroff SK, Bhutada RH, Somani RS, Kasture VS, Kasture S. Clitoria ternatea and the CNS. Pharmacol Biochem Behav 2003; 75: 529-536.

23. Jevoor P, Ravishankar R. Effect of Clitoria ternatea linn plant root extract on the hippocampal area Ca3 and pancreas of juvenile diabetic rats-A preliminary investigation. Spatula DD 2012; 3: 33-79.

24. Kalinichev M, Easterling KW, Plotsky PM, Holtzman SG. Long-lasting changes in stress induced corticosterone response and anxiety-like behaviours as a consequence of neonatal maternal separation in Long-Evans rats. Pharmacol Biochem Behav 2002; 73: 131-140.

25. Kasapoglu M, Ozben T. Alterations of antioxidant enzymes and oxidative stress markers in aging. Exp Gerentol 2001; 36: 209 220.

26. Krinsky NI. Mechanism of action of biological antioxidants. Proc Soc Exp Bio Med 1992; 200: 248-254.

27. Kumari M, Head J, Bartley M, Stansfeld S, Kivimaki M. Maternal separation in childhood and diurnal cortisol patterns in midlife: findings from the Whitehall II study. Psychol Med 2013; 43: 633-643.

28. Lee KY, Miki T, Yokoyama T, Ueki M, Warita K, Suzuki S, Ohta K, Wang ZY, Jamal M, Yakura T, Liu JQ, Hosomi N, Takeuchi Y. Neonatal repetitive maternal separation causes long-lasting alterations in various neurotrophic factor expression in the cerebral cortex of rats. Life Sci 2012; 90: 578-584.

29. Lehmann J, Russig H, Feldon J, Pryce C. Effect of a single maternal separation at different pup ages on the corticosterone stress response in adult and aged rats. Pharmacol Biochem Behav 2002; 73: 141-145.

30. Leichert LI, Gehrke F, Gudiseva HV, Blackwell T, Ilbert M, Walker AK, Strahler JR, Andrews PC, Jakob U. Quantifying changes in the thiol redox proteome upon oxidative stress in vivo. Proc Natl Acad Sci 2008; 105: 8197-8202.

31. Leutner S, Eckert A, Müller WE. ROS generation, lipid peroxidation and antioxidant enzyme activities in the aging brain. J Neural Transm 2001; 108: 955-967.

32. Madhu K. Phytochemical screening and antioxidant activity of in vitro grown plants plants Clitoria ternatea L., using DPPH assay. Asian J Pharm Clin Res 2013; 6: 38-42.

33. Marais L, van Rensburg SJ, van Zyl JM, Stein DJ, Daniels WM. Maternal separation of rat pups increases the risk of developing depressive-like behaviour after subsequent chronic stress byaltering corticosterone and neurotrophin levels in the hippocampus. Neurosci Res 2008; 61: 106-112.
34. Marcadenti A, Coelho RCLA. Dietary antioxidant and oxidative stress: Interaction between vitamins and genetics. J Nutr Heal Food Sci 2015; 3: 1-7.

35. Mukherjee P, Kumar V, Kumar NS, Heinrich M. The Ayurvedic medicine Clitoria ternatea from traditional use to scientific assessment. J Ethnopharmacol 2008; 120: 291-301.

36. Mungli P, Shetty M, Tilak P, Anwar N. Total thiols: biomedical importance and their alteration in various disorders. OJHAS 2013; 8: 1-9.

37. Ohkawa H, Ohishi N, Yagi K. Assay for lipid peroxides in animal tissues by thiobarbituric acid reaction. Anal Biochem 1979; 95 : 351-358.

38. Patil AP, Patil VR. Comparative evaluation of in vitro antioxidant activity of root of blue and white flowered varieties of Clitoria ternatea Linn. Int J Pharmacol 2011; 7: 485-491.

39. Patil AP, Patil VR. Evaluation of in vitro antioxidant activity of seeds of blue and white flowered varieties of Clitoria ternatea Linn. Int J Pharmacy Pharmaceu Sci 2011; 3: 330-336.

40. Prathibha M, Kamath S, Rai K. Comparative efficacy of Choline vs Clitoria ternatea aqueous root extract supplements in attenuating maternal separation stress induced alterations in postnatal rat hippocampus. RJPBCS 2014; 5: 662-668.

41. Prior RL, Cao G. Analysis of botanicals and dietary supplements for antioxidant capacity: a review. J AOAC Int 2000; 83: 950956.

42. Rai KS, Murthy KD, Rao MS, Karanth KS. Altered dendritic arborization of amygdala neurons in young adult rats orally intubated with Clitorea ternatea aqueous root extract. Phytother Res 2005; 19: 592-598.

43. Rai KS, Murthy KD, Karanth KS, Nalini K, Rao MS, Srinivasan KK. Clitoria ternatea root extract enhances acetylcholine content in rat hippocampus. Fitoterapia 2002; 73: 685-689.

44. Rai KS. Neurogenic potential of Clitoria ternatea aqueous root extract - a basis for enhancing learning and memory. WASET 2010; 70: 237-242.

45. Rai KS, Murthy KD, Karanth KS, Rao MS. Clitoria ternatea (Linn) root extract treatment during growth spurt period enhances learning and memory in rats. Indian J Physiol Pharmacol 2001; 45: 305-313.

46. Rizzo AM, Berselli P, Zava S, Montorfano G, Negroni M, Corsetto $P$, Berra B. Endogenous antioxidants and radical scavengers. Adv Exp Med Biol 2010; 698: 52-67.

47. Sachan DS, Hongu N, Johnsen M. Decreasing oxidative stress with choline and carnitine in women. J Am Coll Nutr 2005; 24: 172-176.

48. Santos JC, de Arouzo OR, Valentim IB, de Andrade KQ, Moura FA, Smaniotto S, dos Santos JM, Gasparotto J, Gelain DP, Goulart MO. Choline and cystine deficient diets in animal models with hepatocellular injury: evaluation of oxidative stress and expression of RAGE, TNF- $\alpha$, and IL-1 $1 \beta$. Oxid Med Cell Longev 2015; 2015: 121925.

49. Sapolsky RM. Glucocorticoids, stress, and their adverse neurological effects: relevance to aging. Exp Gerontol 1999; 34: 721732.

50. Sarumathy K, Rajan MS, Vijay T, Jayakanthi J. Evaluation of phytoconstituents, nephro-protective and antioxidant activities of Clitoria ternatea. J Appl Pharma Sci 2011; 1: 164-172. 
51. Sastre J, Pallardo FV, Asuncion JG, Vina J. Mitochondria, oxidative stress and aging. Free Radic Res 2000; 32: 189-198.

52. Sengupta A, Ghosh M. Protective effect of eicosapentaenoic acid- docosahexaenoic acid and alpha linolenic acid rich phytosterol ester on brain antioxidant status and brain lipid composition in hypercholesterolemic rats. Indian J Exp Biol 2013; 51: 241-248.

53. Taranalli AD, Cheeramkuzhy TC. Influence of Clitoria ternatea extracts on memory and central cholinergic activity in rats. Pharm Biol 2000; 38: 51-56.

54. Tsukada H, Kakiuchi T, Fukumoto D, Nishiyama S, Koga K. Docosahexaenoic acid (DHA) improves the age-related impairment of the coupling mechanism between neuronal activation and functional cerebral blood flow response: a PET study in conscious monkeys. Brain Res 2000; 862: 180-186.

55. Uysal N, Gonenc S, Acikgoz O, Pekçetin C, Kayatekin BM, Sonmez A, Semin I. Age-dependent effects of maternal deprivation on oxidative stress in infant rat brain. Neurosci Lett 2005; 34: 98-101.

56. Vinson JA, Dabbagh YA, Serry MM, Jang J. Plant flavonoids, especially tea flavonols, are powerful antioxidants using an in vitro oxidation model for heart disease. J Agric Food Chem 1995; 43: 2800-2802

57. Wu P, Jiang WD, Liu Y, Chen GF, Jiang J, Li SH, Feng L, Zhou XQ. Effect of choline on antioxidant defenses and gene expressions of Nrf2 signaling molecule in the spleen and head kidney of juvenile Jian carp (Cyprinus carpio var. Jian). Fish Shellfish Immunol 2014; 38: 374-382.

58. Yanar K, Aydın S, Cakatay U, Mengi M, Buyukpınarbaşılı N, Atukeren P, Sitar ME, Sönmez A, Uslu E. Protein and DNA oxidation in different anatomic regions of rat brain in a mimetic ageing model. Basic Clin Pharmacol Toxicol 2011; 109: 423-433.

59. Yavin E, Brand A, Green P. Docosahexaenoic acid abundance in the brain: a biodevice to combat oxidative stress. Nutr Neurosci 2002; 5: 149-157.

60. Yen CL, Mar MH, Zeisel SH. Choline deficiency-induced apoptosis in PC12 cell is associated with diminished membrane phosphatidylcholine and sphingomyelin, accumulation of ceramide and diacylglycerol, and activation of a caspase. FASEB J 1999; 13: 135-142.

61. Zeisel SH. Choline: critical role during fetal development and dietary requirements in adults. Annu Rev Nutr 2006; 26: 229250.

62. Zhao HF, Feng L, Jiang WD, Liu Y, Jiang J, Wu P, Zhao J, Kuang SY, Tang L, Tang WN, Zhang YA, Zhou XQ. Flesh shear force, cooking loss, muscle antioxidant status and relative expression of signaling molecules (Nrf2, Keap1,TOR, and CK2) and their target genes in young grass carp (Ctenopharyngodon idella) muscle fed with graded levels of choline. PLoS One 2015; 10: e0142915. 